\title{
A bela Junie: a questão do duplo vai à tela do cinema
}

\author{
Rodrigo Fontanari* \\ Doutorando e mestre pela Pontifícia Universidade Católica de São Paulo. \\ E-mail: jrpfpub@hotmail.com
}

Resumo: O presente artigo parte da questão do duplo aplicado a uma leitura da fotografia, mais especificamente do retrato fotográfico. A imagem aprisionada adquire qualidade de projeção, e esta assume para a consciência o papel de uma entidade autônoma que sobrevive ao sujeito no qual fundamentou a sua gênese, partilhando com ele certa identificação. Estamos diante de um paradoxo: a foto como duplo do outro se revela, ao mesmo tempo, como a presença de uma ausência e a ausência de uma presença. Para analisar o papel antropológico da fotografia como duplo, elegemos como corpus o filme A bela Junie.

Palavras-chave: duplo, imagem, fotografia, retrato fotográfico, A bela Junie.
Abstract: This article is based on the matter of the double applied to reading a photograph, especially a portrait. Such an imprisoned image acquires projection quality and becomes concious, playing the role of an autonomous entity which survives the subject who grounded its genesis, sharing a certain identification with him. A paradox is before us: the photograph, as a double, reveals itself at the same time as the presence of an absence, and the absence of a presence. We chose the film La belle personne in order to analyze the anthropological role of the photograph.

Keywords: double, image, photograph, portrait, La belle personne.

Em busca do entendimento da questão do duplo, optaremos por uma pesquisa em dois caminhos metodológicos de explicação: um sociológico, pelas mãos de Edgar Morin, e outro psicológico, dado por Otto Rank. Não obstante, ao que se refere ao campo de reflexão da fotografia, elencamos para o embasamento teórico um diálogo investigativo com Michel Tournier, Roland Barthes, Susan Sontag e Walter Benjamin.

Segundo o entendimento de Morin $^{1}$, a questão do duplo emerge a partir da pré-história do sapiens, quando este toma consciência da morte. Portanto, a partir do momento que há a irrupção da consciência, ocorrerá uma dissociação incômoda ao ser humano, já que até então o homem não sabia o que era viver em estado de divisão.

Segundo o mesmo autor, por meio da consciência da morte que deu origem a essa dissociação básica e ao surgimento da consciência, emerge a questão do duplo, que nada mais é do que suportes através dos quais se manifesta o

Recebido: 20.04.2009

Aprovado: 19.08.2009

* Endereço para acessar este CV: <http://lattes.cnpq. br/9284759706362600>.

1. MORIN, Edgar. O paradigma perdido. Portugal: Europa-América, 1988. 
comunicação \& educação • Ano XV • número 2 • maio/ago 2010

imaginário humano. São suportes simbólicos e materiais que se aderem e se contaminam com a ideia da morte e da sua outra face, a sobrevida simbólica. Uma de suas manifestações é a sombra (primeira percepção de si do homem), e essa questão do duplo (sombra) remete também à questão das imagens. "[...] o tema do duplo que já emergiu ao propósito do duplo é atestado pela sombra móvel que acompanha cada um, pelo desdobramento da pessoa no sonho e pelo desdobramento do reflexo na água, quer dizer, a imagem." ${ }^{2}$

Independentemente do suporte (reflexo na água, sombra projetada na parede, uma fotografia), as imagens contêm em si a ideia do duplo:

Desde então, a imagem não é só uma imagem, mas contém a presença do duplo do ser representado e permite, por seu intermédio, agir sobre esse ser; é esta ação que é propriamente mágica: rito de evocação pela imagem, rito de inovação à imagem, rito de possessão sobre a imagem (enfeitiçamento) $[\ldots]^{3}$.

No ritual mágico, o Homo sapiens não recorre simplesmente aos seres que podem fornecer resposta, mas também às imagens e símbolos, pois entende que encontrará aí as respostas requeridas. Inaugura, assim, uma ligação imaginária com o mundo. Considera-se uma segunda existência, visto que o Homo sapiens passa a operar por imagens mentais que estão fora da percepção empírica. Esse homo sapiens de que fala Morin dialoga e inaugura uma ligação com o mundo por meio da imagem para solucionar sua angústia e ansiedade primeira, que é o medo da morte: a busca pelo eterno, em detrimento da transitoriedade desse indivíduo, fá-lo-á buscar símbolos que perpetuem e garantam a sua existência.

Enfim, o que demonstra Edgar Morin ${ }^{4}$ é que a consciência da morte abriu um mundo mágico em que as coisas, as representações icônicas das coisas reais e mesmo as palavras adquiriram um poder evocativo e invocativo, a ideia do duplo. Essa ruptura, através da qual as coisas adquirem dupla existência, Morin a denominou segunda existência, em que há existência apenas numa forma mental, fora da percepção empírica, semelhante à imagem que forma a percepção, que não passa de uma imagem relembrada, ou seja, imaginação. A partir daí esse Homo sapiens passa a viver num mundo imaginário, por meio do qual busca aplacar o medo da morte, utilizando-se para tanto da magia e do rito como um exercício de superação das suas condições primeiras. Referindo-nos à capacidade invocativa e evocativa do duplo, temos:

Assim, o mundo exterior, os seres e os objetos do ambiente adquirem, com o Homo sapiens, uma segunda existência, a existência sob a forma de uma imagem mental, análoga à imagem que forma a percepção, visto que não se trata senão dessa imagem relembrada. [...] todo o significante, incluindo o sinal convencional, transportará potencialmente a presença do significado (imagem mental) e esse último poderá confundir-se com o referente, isto é, com o objeto designado ${ }^{5}$.

Numa perspectiva de leitura mais psicanalítica da questão do duplo, como nos possibilita Otto $\operatorname{Rank}^{6}$, essa inquietação está intimamente relacionada às origens mais anciãs da espécie humana: a crença na imortalidade. Nessa 
perspectiva, a sombra e a imagem são uma representação em que o sujeito (o eu) se torna independente. Por ser inseparável do homem, a sombra tornou-se uma das objeções para alma humana, pois é a partir dela que o indivíduo pode ver seu corpo pela primeira vez.

O duplo eu tinha precisamente a função primeira de negar a morte e garantir a imortalidade do ser na medida em que ao menos a sombra (duplo) continuaria a viver após o desaparecimento do corpo (eu corporal). Essa é a crença primitiva da dualidade da alma (corpo e sombra) sobre a qual repousa toda uma problemática a respeito da sombra: ela é um paradoxo porque significa a vida e a morte. As duas partes - corpo e alma, ou corpo e sombra - são ao menos um pouco iguais, pois não é possível dissociar uma da outra. Existe um vínculo umbilical entre elas: o representante (o referente) e a coisa representada (a sombra). No entanto, o que as difere completamente é a sobrevivência simbólica: um desaparece (o corpo) enquanto a outra continua (a alma).

\section{A FOTOGRAFIA, UM REGISTRO MÁGICO?}

A obsessão humana de fixar a imagem produzida na parede interna da caixa-preta (câmera obscura) vingou nas mãos de Niepce e Daguerre, que são os inventores da técnica fotográfica do lado francês. Esse tipo de imagem antropologicamente nova - a possibilidade de fixar e apreender para sempre a sombra do outro - teve seu nascimento no século XIX, por volta de 1822.

Esse tipo de imagem modifica o conceito de representação $\operatorname{artística~}^{7}-\mathrm{o}$ retrato feito pelas mãos do próprio artista, considerado um ser divino, dotado de poder celestial, o único que poderia se atrever a tal façanha. Mas a entrada em cena da produção técnica de imagem (o retrato fotográfico) introduz também uma outra perpelexidade, assinalada logo nas primeiras linhas do texto de Benjamin: o que há de mais técnico parece o que há de mais mágico. Benjamin escreve: "A técnica mais exata pode conferir aos seus produtos um valor mágico"s.

Havia algo antropologicamente espantoso entre o retrato produzido pelas mãos do artista e a representação técnica feita pelas mãos do fotógrafo: a nitidez dessas fisionomias que dava a impressão de que os pequenos rostos humanos que apareciam na imagem eram capazes de nos ver. E, à medida que fomos sendo colonizados por esse tipo de imagem, mais ainda essa técnica deu às suas criações um valor mágico que o quadro e o artista não podiam dar. Sobre isso, afirma Benjamin:

[...] o observador sente a necessidade irresistível de procurar nessas imagens a pequena centelha do acaso, do aqui e agora, como a qual a realidade chamuscou a imagem, de procurar o lugar imperceptível em que o futuro se aninha ainda hoje em minutos únicos, há muito instinto, e com tanta eloquência que podemos descobri-lo, olhando para trás. A natureza que fala à câmara não é a mesma que fala ao olhar; é outra, especialmente, porque substitui a um espaço trabalhado conscientemente pelo homem, um espaço que ele percorre inconscientemente ${ }^{9}$.
7. Para maiores esclarecimentos, sugerimos a leitura do capítulo: A arte é (tornou-se) fotografia? In: DUBOIS, Philippe. $O$ ato fotográfico. Campinas: Papirus, 1994.

8. BENJAMIN, Walter. Textos escolhidos. São Paulo: Victor Civita, 1983. p. 94.

9. Ibid. 
comunicação \& educação • Ano XV • número 2 • maio/ago 2010

Benjamin fala em inconsciente a propósito da fotografia. Como espaço técnico, a fotografia tem seu caráter mágico associado à possibilidade de adentrar por meio da imagem num abissal denominado espaço do inconsciente. Desenvolve-se diante de tal realismo e verdade certa afetividade, por trazer para dentro do quadrante a alma do sujeito fotografado. De maneira muito direta, a fotografia é a pura emanação do referente.

\section{DE A BELA JUNIE}

O longa-metragem francês $L a$ belle personne chegou às salas de cinema do Brasil em primeiro de janeiro de 2009, sob o título A Bela Junie. É um filme de Christophe Honoré baseado no romance La Princesse de Clèves, de Madame Lafayette, escrito no século XVIII. Totalmente rodado na bela Paris, um cenário considerado propício para cenas de amor que ocorrem no $16^{\circ}$ arrondissement $^{10}$, La belle personne traz à tela de cinema um tema corriqueiro dos romances: o amor romântico, arrebatador e impetuoso de uma adolescente de beleza encantadora. Aos dezesseis anos, Junie (Léa Seydouxde) muda de escola no meio do ano letivo, por ocasião da morte de sua mãe. Ela passa a frequentar a mesma sala de aula que seu primo Mathias (Esteban Carjaval Alegria). O primo cuida rapidamente de enturmá-la em seu grupo de amigos. A bela Junie é logo cortejada pelos garotos e se torna namorada de Otto (Grégoire Leprince-Ringuet), o menino mais calmo e tímido do grupo.

10. Os arrondissements (distritos) correspondem uma divisão administrativa que decompõe a comuna de Paris em 20 arrondissements municipais distribuídos segundo uma espiral que se desenvolve no sentido dos ponteiros do relógio a partir de um ponto central da cidade localizado no Louvre (10 arrondissement). (N.E.)

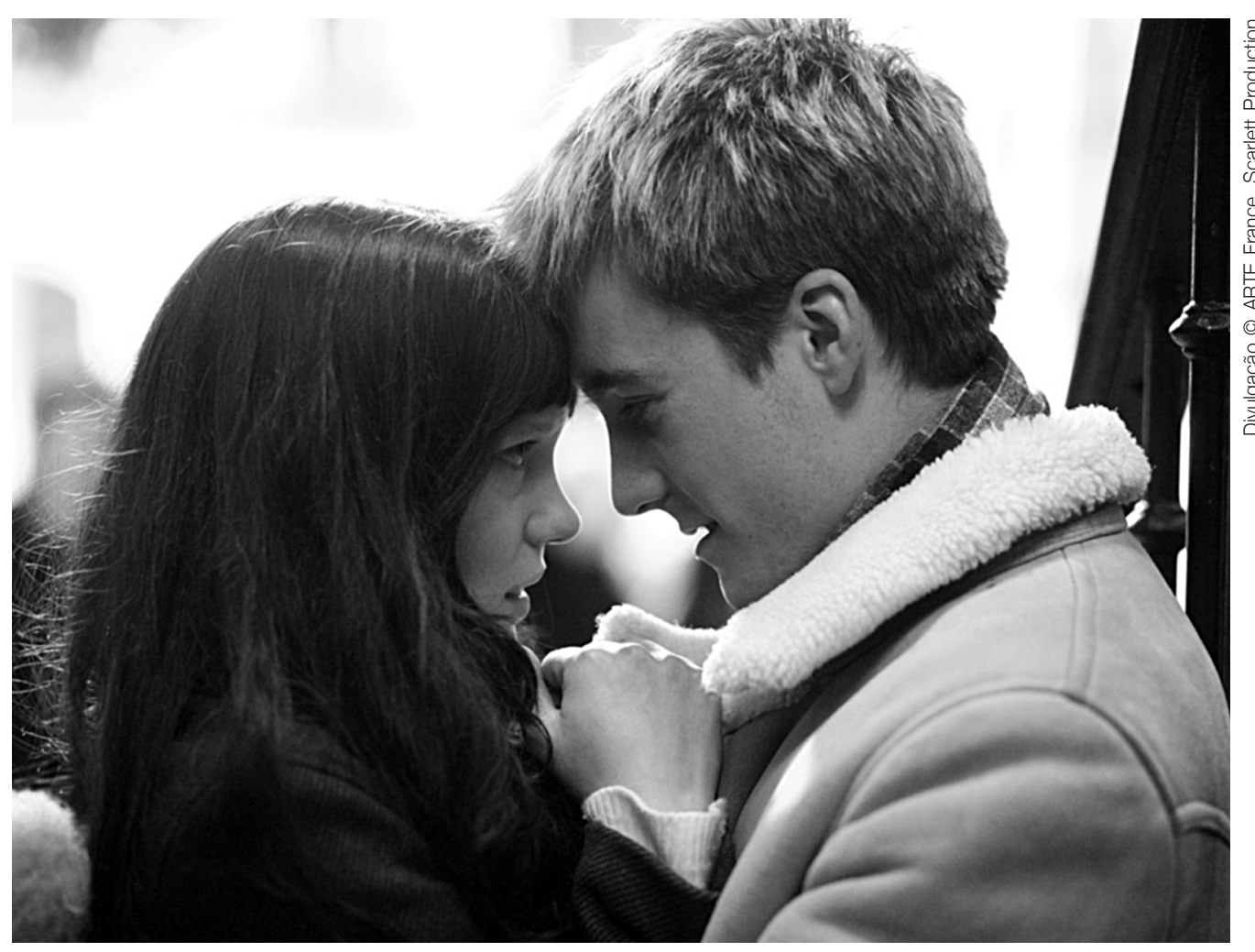

Otto e Junie: o amor romântico. 
Pouco tempo depois, ela se dá conta de que está apaixonada pelo professor de italiano Nemours. A paixão que nasce entre eles está fadada ao fracasso, já que nenhum deles quer ceder àquele sentimento. Junie recusa o amor do professor por achar que se trata de pura ilusão da parte dela. O sentimento amoroso entre Junie e Nemours acontece subitamente durante a aula de italiano, no momento em que ele nota a beleza desarmada e fértil da adolescente.

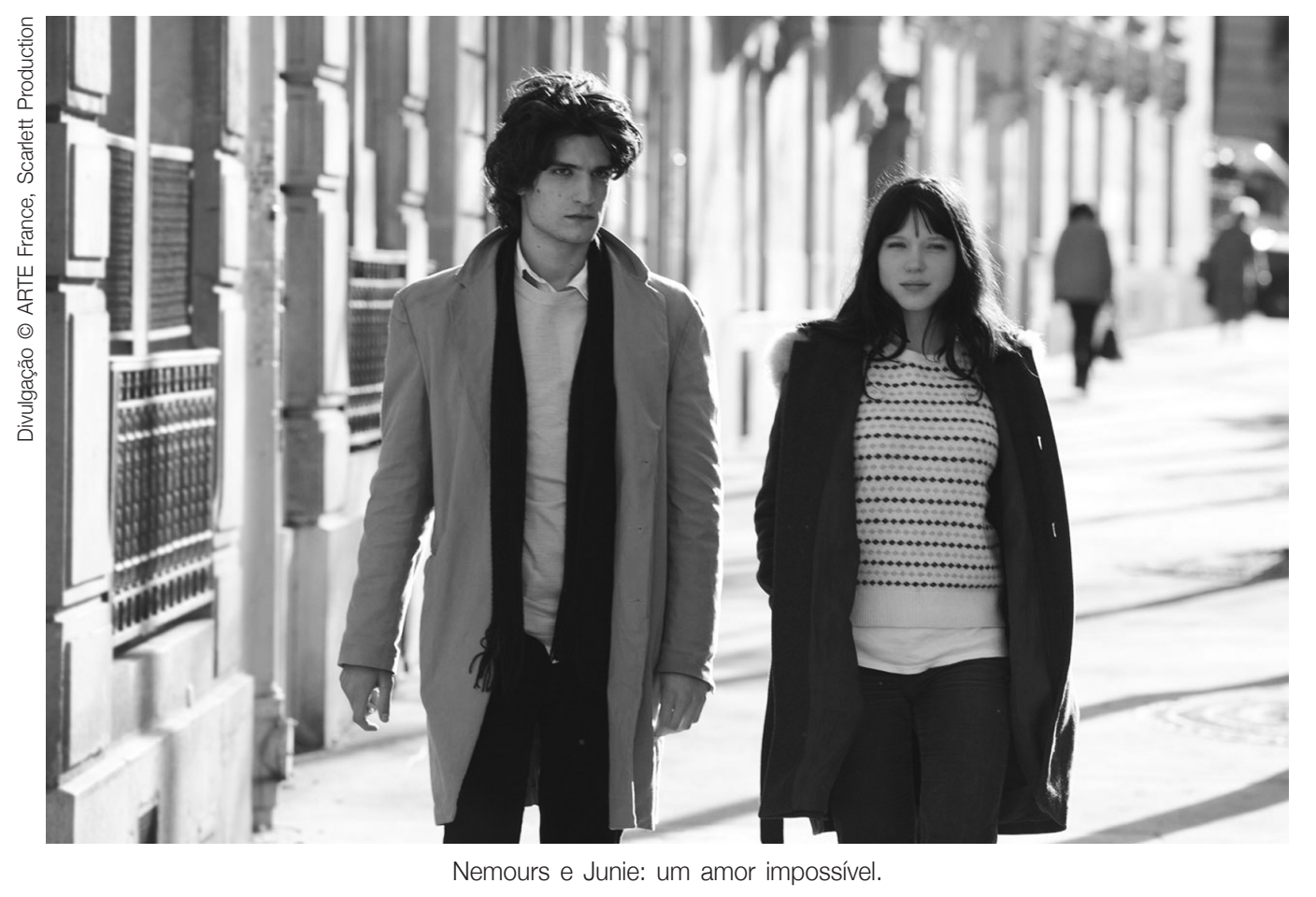

\section{POR UMA SEMIÓTICA SENSÍVEL DA FOTOGRAFIA}

Interessamo-nos por A bela Junie não para fazer a crítica do filme, mas porque ele possibilita desenvolver um olhar mais periférico e aguçado sobre o papel da fotografia no desenrolar da trama cinematográfica. Há diversas cenas no portão de entrada do lycée em que um dos adolescentes, fascinado por fotografias, passa a fotografar Junie. Ele lhe entrega uma das fotos em preto e branco, que ela guarda no meio das folhas do seu caderno de notas. Certo dia, durante a aula de italiano, Nemours observa que Junie havia esquecido seu caderno de notas sobre a carteira e passa a folheá-lo. Quando encontra um retrato dela, passa a contemplá-lo apaixonadamente. Poderíamos dizer que o professor de italiano se apaixona duplamente, pela adolescente e pela (sua) imagem fotográfica. A fotografia dava-lhe a sensação de que, pelo menos no plano da imaginação, ele poderia possuí-la amorosamente.

Deixar-se fotografar altera semioticamente o ser: "Fotografar pessoas é violá-las, ao vê-las como elas nunca se veem, ao ter delas um conhecimento que elas nunca podem ter, transformar as pessoas em objetos que podem ser simbolicamente possuídos"11.

11. SONTAG, Susan. Sobre fotografia. São Paulo: Companhia das Letras, 2004. p. 25. 
comunicação \& educação • Ano XV • número 2 • maio/ago 2010

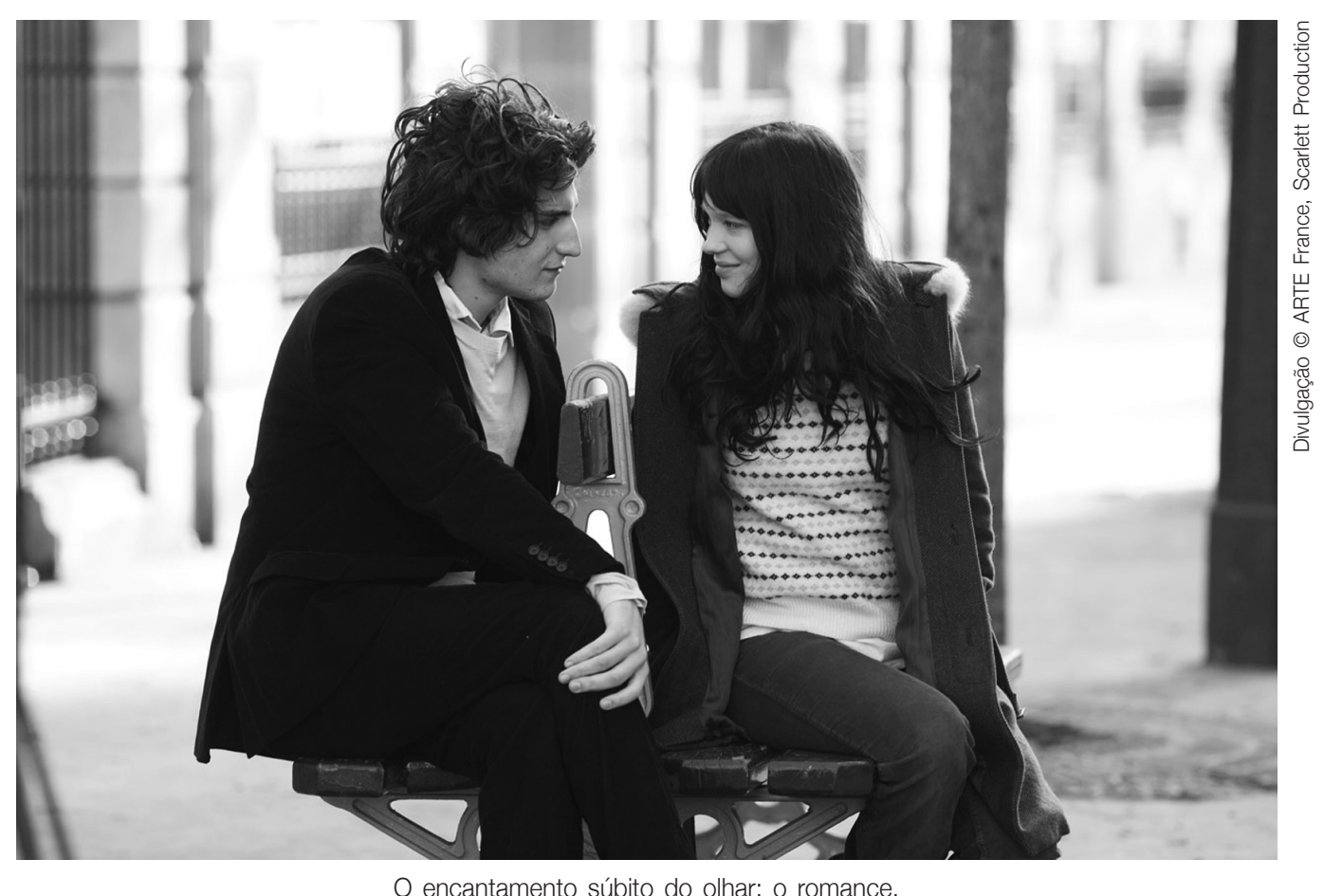

O ser fotografado constroi-se pelo olhar do outro (o fotógrafo) e o retrato que se produz dele é uma forma de ver o que o próprio olhar do indivíduo não consegue fazer de si mesmo - salvo a imagem no espelho, mas ali tudo é temporário -, transformando em um objeto de culto um verdadeiro duplo (imagem espelhada) de si.

De maneira mais pontual, Roland Barthes apresenta em A câmara clara o papel semiótico da fotografia:

[...] é o advento de mim mesmo com outro: uma dissociação astuciosa da consciência de identidade [...] não sou nem sujeito nem objeto, mas antes sujeito que se sente tornar-se objeto: vivo então uma microexperiência da morte [...] torno-me verdadeiro espectro ${ }^{12}$.

Se a fotografia culturalmente assume o papel de objeto de culto (o objeto fotografado transformado em espectro que se eterniza no quadrante fotográfico), podemos tomar a foto de Junie com um disparador do romance: um sonho, uma ficção. Nas palavras de Susan Sontag, "[...] as fotos - sobretudo as de pessoas, de paisagens distantes e de cidades remotas do passado desaparecido - são estímulos para o sonho"13.

A narrativa cinematográfica corrobora o pensamente dessa autora: a partir

12. BARTHES, Roland. A câmara clara: nota sobre fotografia. Rio de Janeiro: Nova Fronteira, 2004. p. 87.

13. SONTAG, op. cit., p. 26. do momento que Neumors tem a foto de Junie, o que ele mais faz é praticar o ato de contemplar a imagem fotográfica, de pousar seu olhar novamente sobre a imagem do ser amado e desejado. Era como tê-la cada vez mais perto e, ao mesmo tempo, não poder tocá-la.

Esse incessante ato de vigília da imagem fotográfica (de vigília amorosa do sujeito) fazia-o adentrar uma segunda existência, uma experiência mágica em 
que seus sonhos eróticos e amorosos mais profundos poderiam ser realizados. Para Sontag: "Todos esses usos talismânticos das fotos exprimem uma emoção sentimental e um sentimento implicitamente mágico: são tentativas de contatar ou de pleitear outra realidade" ${ }^{\text {. }}$.

De qualquer maneira, parece que a fotografia, na qualidade de fato de cultura, serve a uma dupla função de arte e magia, como afirma Benjamin, mas também é uma forma de informação. Michel Tournier completa a função cultural da fotografia: para ele, além de ser algo mágico e possibilitar alguém de se informar sobre alguma coisa, é também uma forma de expansão do erotismo. De maneira poética, ele diz:

Entre as vias de expansão do erotismo que conquistam, a fotografia ocupa um lugar privilegiado. Já a imagem pintada, esculpida, seguidamente impressa carregava com ela uma carga erótica intensa, como o vento da primavera das toneladas invisíveis de pólen. Com a fotografia, a distância entre o modelo e o espectador diminui consideravelmente. O valor criador desta imagem diminui igualmente, mas a sua eficácia erótica aumenta. Possuir a fotografia do ser desejado é uma grande satisfação $[\ldots]^{15}$. (Tradução livre.)

Portanto, há na imagem fotográfica algo muito mais mágico (duplo) do que artístico, que suscita o imaginário, o erotismo, quando isso está exposto. Nela está implícita uma capacidade de ter para si aquilo que se deseja, mas que por diferentes razões está ausente. Ainda assim, sente-se por meio de sua imagem a mesma satisfação momentânea que se estivesse presente. A fotografia é puro delírio, é puro sonho, quando lida pelo viés de uma semiótica do sensível que leva em conta uma antropologia da comunicação visual.

Nesse sentido, a importância cultural e social da fotografia no filme não cessa de ser demonstrada. Podemos afirmar que, além de estar claro de que toda foto (imagem) é um paradoxo, ela é também uma ausência de uma presença e, ao mesmo tempo, a presença de uma ausência. Em La belle personne, suspeitamos que a imagem fotográfica nos leve a outra figura de palavra: a metonímia. Tudo o que resta a Neumours é a foto da amada (isso é tudo o que ele possui de concreto,), pois, de resto, tudo não passou de um jogo de olhares.

No filme, a foto faz o papel de um meio vinculador, de certo modo até umbilical, com o sujeito fotografado, se aceitarmos que ele é resultado da emanação de luz desse referente. Se perseguirmos essa mesma hipótese fotográfica, diante de uma foto, estaríamos diante do que o semiótico Charles Pierce denominou de índice - signo que mantém certa contiguidade com o referente -, tese amplamente defendida por Philippe Dubois ${ }^{16}$. Indo ao encontro do pensamento de Dubois, defrontamo-nos com as hipóteses de Flusser, para o qual a fotografia é o resultado da programação interna do aparelho (caixa-preta): um embuste em relação ao referente. Assim, a imagem fotográfica é como uma imagem conceitual: produto de uma ideia que está embutida no programa do aparelho. Resta ao fotógrafo somente jogar com as possibilidades desse programa, entendido como "jogo de combinação com elementos claros e distintos"17.
14. Ibid., p. 27.

15. TOURNIER, Michel Des clefs et des serrures: images et proses (Chaves e fechaduras: imagens e prosas). Paris: Chaîne/ Hachettte, 1979. p. 98.

16. DUBOIS, Philippe. O ato fotográfico. Campinas: Papirus, 1994.

17. FLUSSER, Vilém. Filosofia da caixa-preta: ensaios sobre uma futura filosofia da fotografia. Rio de Janeiro: Relume Dumará, 2002. p. 78. 
comunicação \& educação • Ano XV • número 2 • maio/ago 2010

Nesse sentido, ao tomarmos a foto como uma escrita da luz sobre o papel (sais de prata), é bem improvável que a imagem resultante sobre o papel fotográfico não crie um vínculo entre o sujeito fotografado e o observador, principalmente quando esse sujeito fotografado não desapareceu:

[...] a foto do ser desaparecido vem me tocar como os raios retardados de uma estrela. Uma espécie de vínculo umbilical liga a meu olhar o corpo da coisa fotografada: a luz, embora impalpável, é aqui um meio carnal, uma pele que partilha como aquele que foi fotografado ${ }^{18}$.

Se naquele momento Neumours não pode ter o seu sujeito amado, resta-lhe ainda, pelo menos, a foto para contemplar e desejar a bela Junie.

O filme é repleto de fotos. No próprio lycée, o retrato fotográfico é tomado como memória dos alunos. Portanto, a foto é uma forma de viver e reviver:

[...] ela realiza a confusão inaudita da realidade ("isso foi") e da verdade ("é isso"), [...] ela leva a efígie a esse ponto louco em que o afeto (o amor, a compaixão, o luto, o ardor, o desejo) é fiador do ser. Ela então se aproxima efetivamente da loucura, reunindo-se à "verdade louca"

Ao final do filme, é quase impossível não imaginar as tardes frias de Paris, quando aquele professor de italiano permanecia olhando para a foto de Junie, o que leva também a pensar na foto como uma excelente forma de anotação e uma máquina de fazer sonhar e de romancear o mundo: é pura nostalgia do isso existiu ( $C$ a a été). Não lhe resta - nem a nós mesmos, como espectadores do filme - mais nada a fazer senão se deixar levar na contemplação do retrato fotográfico, uma vez que aquela cena ou pessoa não pode mais ser tocada (ela está morta e congelada pelo menos temporalmente). Para Barthes, aí estava o horror fotográfico:

[...] nada a dizer da morte de quem eu mais amo, nada a dizer de sua foto, que contemplo sem jamais poder aprofundá-lo, transformá-lo. O único "pensamento" que posso ter é que no extremo dessa primeira morte está inscrita minha própria morte, entre as duas, mais nada [...] falar do nada a dizer ${ }^{20}$.

Portanto, há algo semioticamente sensível que emerge entre a fotografia e a loucura (duplo): o sofrimento de amor, compaixão, luto, ardor, desejo que brota desse tipo de imagem, com qual guardo um duplo vínculo de amor e de luto.

Aí, diante da imagem, a linguagem cessa e o corpo se deixa guiar pelos sentidos em busca do sensível de um tempo perdido, que não é o tempo que se perde, mas aquele que não volta mais. Tudo é dado, sem provocar a vontade ou mesmo a possibilidade de retórica, somente a necessidade súbita de grito histérico: é isso, é ela, a bela Junie!

Estamos diante do sinistro fotográfico; na medida em que aquele retrato

18. BARTHES, op. cit., p. 124.

19. Ibid., p. 168.

20. Ibid., p. 138. fotográfico tinha tal capacidade de realismo (ele era real), Neumours podia sentir a presença de Junie novamente. Conscientemente ou não, o professor desejava esquecê-la, pois a angústia da perda era sofrível demais para ele. A cada golpe de olhar que dava sobre a foto, mais evidente e profunda se tornava 
a dor da ausência e da perda insuportável, o que por sua vez tornava angustiante o afeto sentido por ela, que não podia mais ser demonstrado e vivido pelas personagens. Restam então o luto e a dor da perda: uma categoria do sinistro freudiano, o retorno do recalcado (o amor pela jovem lycéeana). Assim sendo, "se o que era entranhável aparece depois como alheio é porque essa imagem que se vê agora, já foi vista [percebida] antes, sendo desprazerosa vê-la [percebê-la] novamente" ${ }^{21}$.

\section{REFERÊNCIAS BIBLIOGRÁFICAS}

BARTHES, Roland. A câmara clara: nota sobre fotografia. Rio de Janeiro: Nova Fronteira, 2004.

BENJAMIN, Walter. Textos escolhidos. São Paulo: Victor Civita, 1983.

CESAROTTO, Oscar. No olhar do outro: o homem de areia segundo Hoffmann. São Paulo: Iluminuras, 1996.

DUBOIS, Philippe. Cinema, vídeo e Godard. São Paulo: Cosac Naify, 2004. O ato fotográfico. Campinas: Papirus, 1994.

FLUSSER, Vilém. O mundo das imagens técnicas. São Paulo: Annablume, 2008. Mundo codificado. São Paulo: Cosac Naify, 2007.

Filosofia da caixa-preta: ensaios sobre uma futura filosofia da fotografia. Rio de Janeiro: Relume Dumará, 2002.

MORIN, Edgar. O paradigma perdido. Portugal: Europa-América, 1988.

RANK, Otto. Don Juan et le Double (Don Juan e o duplo). Paris: Petit Bibliothèque Payot, 1977.

SONTAG, Susan. Sobre fotografia. São Paulo: Companhia das Letras, 2004.

TOURNIER, Michel. Des clefs et des serrures: images et proses (Chaves e fechaduras: imagens e prosas). Paris: Chaîne/Hachettte, 1979.

21. CESAROTTO, Oscar. No olhar do outro: o homem de areia segundo Hoffmann. São Paulo: lluminuras, 1996. p. 134. 


\section{Assine a revista Comunicação \& Educação}

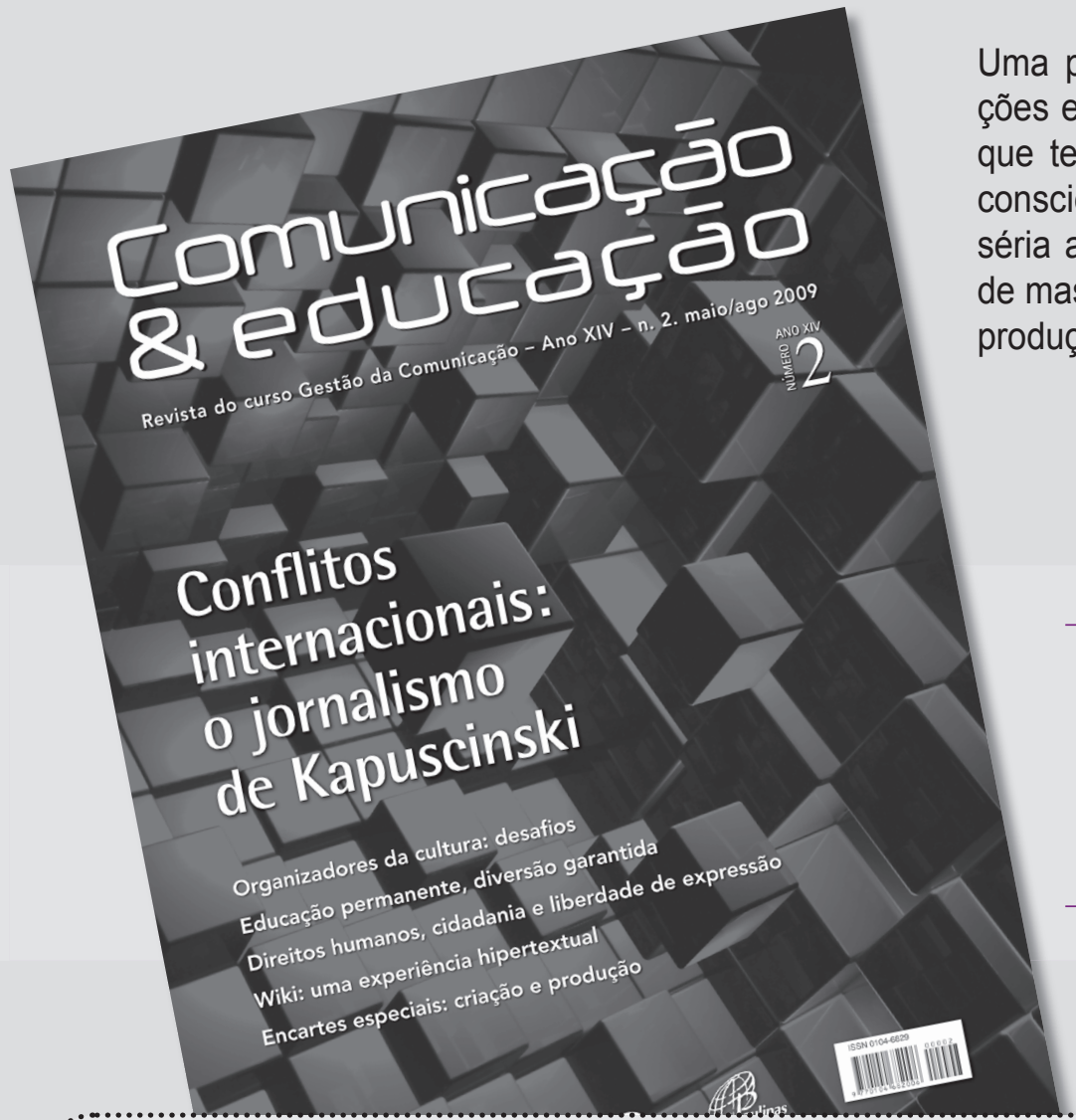

Uma parceria de Paulinas com a Escola de Comunicações e Artes, da Universidade de São Paulo (ECA-USP), que tem por objetivo ajudar a formar profissionais mais conscientes, críticos e interativos, por meio da discussão séria a respeito da natureza dos meios de comunicação de massa, dos direitos da audiência e da crítica estética à produção midiática.

\section{Revista Comunicação \& Educação}

Periodicidade: quadrimestral

\section{Ensaios, entrevistas e debates com os maiores especialistas da área auxiliam educadores a incluir em suas práticas novas linguagens e novos recursos pedagógicos.}

\section{ADQUIRA TAMBÉM OS EXEMPLARES AVULSOS!}
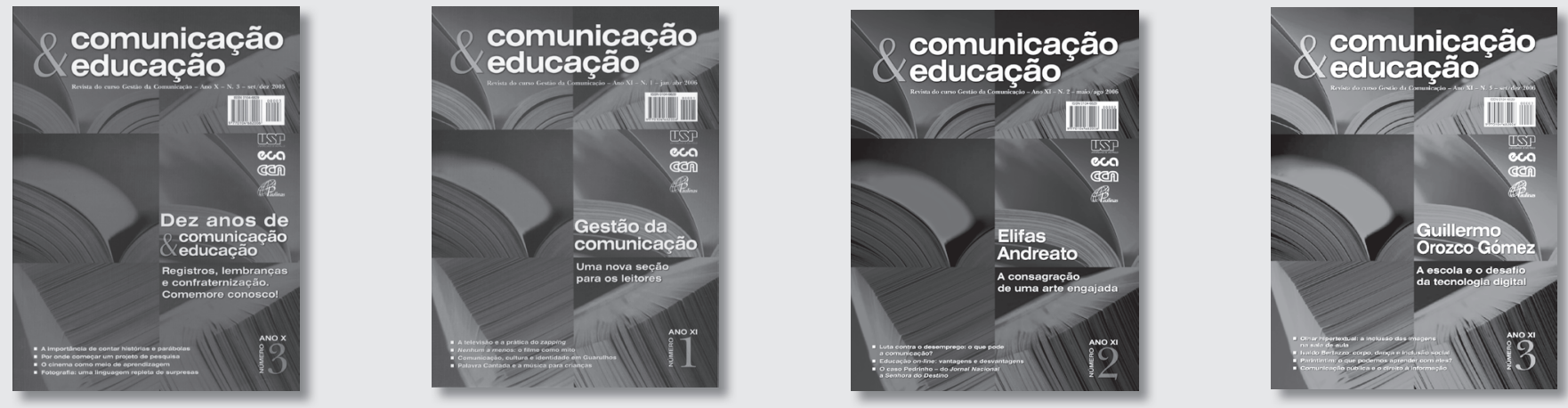

\section{VOCÉ ESCOLHE COMO QUER PAGAR!}

- Cartão de crédito - Visa, Mastercard ou Dinners • Boleto bancário

- Depósito bancário identificado • DOC ou transferência bancária

Ligue 0800-7010081 ramal 9448 ou assine

pela livraria virtual Paulinas, acessando www.paulinas.org.br Informações: livirtual@paulinas.com.br 